\title{
Optimization of Network Carbon Capture and Storage System (CCS) Using Mathematical Approach
}

\author{
David Licindo ${ }^{1}$, Arinne Christin Paramudita ${ }^{1}$, Renanto Handogo ${ }^{1} \&$ Juwari Purwo Sutikno ${ }^{1}$ \\ ${ }^{1}$ Department of Chemical Engineering, Institut Teknologi Sepuluh Nopember, Indonesia \\ Correspondence: David Licindo, Department of Chemical Engineering, Institut Teknologi Sepuluh Nopember, \\ Surabaya, 60111, Indonesia. E-mail: renanto@chem-eng.its.ac.id
}

Received: May 4, 2015

Accepted: June 5, 2015

Online Published: June 30, 2015

doi:10.5539/mas.v9n7p161

URL: http://dx.doi.org/10.5539/mas.v9n7p161

\begin{abstract}
Carbon capture and storage (CCS) is one of the technologies to reduce greenhouse gas emissions (GHG) to capture of $\mathrm{CO}_{2}$ from the flue gas of a power plant that typically use coal as a Source of energy and then store it in a suitable geological storage (in specific locations). In practice, these sites may not be readily available for storage at the same time that the Sources (GHG producing) are operating which gives rise to multi - period planning problems. This study presents a mathematical approach by considering constraints limit flowrate received by Sink, various time availability of Sink and Source and calculation with the purpose to determine the minimum cost network which is getting the maximum load that is exchanged from Source to Sink. Illustrative case studies are given to demonstrate the application of mathematical models to obtained with the exact result of the exchange network from Source to Sink. Derived from network obtained from the calculation of the Maximum Load Source to Sink and results may vary in accordance with the limitations that exist in the mathematical model. The case study has been prepared with 2 cases, first 6 Source and 3 Sink with value of Source Load is greater than the amount available on the Sink. Also, second case is 2 Source and 5 Sink with value of Source Load is smaller than the amount available on the Sink. In addition, Case Studies to minimize the cost of pipeline construction and distribution of $\mathrm{CO}_{2}$ by plant and storage location determination in Java. Flowrate restriction factor that goes into Sink, Source and Sink establishment time and cost are taken into account can affect the networks that can be exchanged from the Source to the Sink.
\end{abstract}

Keywords: carbon capture and storage system, mathematical approcah, source-sink, optimization, carbon capture

\section{Introduction}

\subsection{Introduce the Problem}

Today the issue of global warming is getting warm to talk about. Over the last few years, all human activity is causing the greenhouse effect is increasing. Carbondioxide $\left(\mathrm{CO}_{2}\right)$ is one component in the amount of greenhouse gases in the atmosphere at most. The industrial sectoris the largest contributor to carbon emissions. One of the possible solutions is to use carbon capture and storage technology system (CCS). The concept of CCS in general is the reduction of emissions from large industrial sources by capturing the $\mathrm{CO}_{2}$ from the exhaust gases and subsequently storing it in appropriate geological storage sites. The storage sites may be depleted oil and gas fields, saline acquifers, coal seams and other similar formations (Davison et al., 2001; Pires et al., 2011).

The International Energy Agency (IEA) has indicated that to reach a target emissions level of $14 \mathrm{Gt} / \mathrm{y}$ by 2050 , CCS will have to contribute $19 \%$ of the reductions (approximately $9 \mathrm{Gt} / \mathrm{y}$ of $\mathrm{CO}_{2}$ reductions out of $48 \mathrm{Gt} / \mathrm{y}$ ) (IEA, 2010). Geological reservoirs worldwide have been evaluated and it is estimated that there is a potential storage capacity of $236 \mathrm{Gt}$ of $\mathrm{CO}_{2}$, or approximately three decades of storage (Strangleand 2007).

In practice, these sites may not be readily available for storage at the same time or when the source operates before operating sources which gives rise to multi-period planning problems. At the same time the Source and Sink can be grouped geographically to minimize the need (cost) for $\mathrm{CO}_{2}$ transport over long distances.

\subsection{Recent Research}

Lately, optimal planning for $\mathrm{CO}_{2}$ transport infrastructure to match the flow source, such as power plants and industrial facilities with proper Sink or storage sites, is recognized as an important prerequisite for successful 
commercialization of CCS (Brunsvold et al., 2011). Similar work has also been done in the United States (Ambrose, et al., 2009) and developing countries such as China and India (Condor et al., 2011). At the same time, other researchers have attempted to develop a model to provide decision support for matching Source - Sink $\mathrm{CO}_{2}$. For example, Turk et al. (1987) did early attempts to model the optimal matching Source - Sink $\mathrm{CO}_{2}$ for EOR purposes using integer linear programming model of the pure.

More recently, a heuristic algorithm for the design of CCS pipeline proposed by Kazmierczak et al. (2009). This recursive approach allows for a gradual adjustment of the capacity of the network from time to time, but do not involve direct optimization. Middleton and Bielicki (2009) developed a model SimCCS, which uses a mixed integer linear programming (MILP) formulation which combines the decisions about infrastructure characteristics (eg, size of pipe) in a static framework. Pekala et al., (2010) describes the planning model based on the optimal energy. Diamante et al., (2013) and Tan et al., (2013) describes unification-based model injectivity with a multi-period approach presented in. In all pinch analysis approach, the quantity and quality of the sources and the sinks are determined first.

\subsection{Purpose of this Study}

In this work, a simple model of programming algorithm with mathematical approach was developed to optimization models for matching Source - Sink temporal periods, the level of injectivity, and storage capacity constraints. This model requires data to be determined for both the $\mathrm{CO}_{2}$ source (ie: rate of $\mathrm{CO}_{2}$ from power plants with carbon capture (CC) and the start time of operation) and Sink (ie: $\mathrm{CO}_{2}$ storage capacity, injection rate limit (absorption) of $\mathrm{CO}_{2}$, and the time availability). By using the data input, this model can automatically determine the allocation of $\mathrm{CO}_{2}$ networks by maximizing the amount of $\mathrm{CO}_{2}$ that is captured and stored in the system that has been granted. The objective is to determine the minimum amount of unutilized $\mathrm{CO}_{2}$ storage capacity by matching $\mathrm{CO}_{2}$ sources and sinks, given these specified temporal and physical constraints. This is also equivalent to maximizing total $\mathrm{CO}_{2}$ captured and stored with hope for the future, this model can be used for planning of CCS in Indonesia.

\section{Method}

The In this work, developed a mathematical approach to optimization models matching Source - Sink in the temporal period, the level of injectivity, and storage capacity constraints. This model requires data specified for both the $\mathrm{CO}_{2}$ source (ie: rate of $\mathrm{CO}_{2}$ from power plants with carbon capture (CC) and the start time of operation) and Sink (ie: $\mathrm{CO}_{2}$ storage capacity, injection rate limit (absorption) of $\mathrm{CO}_{2}$, and time availability). By using the data input, this model can automatically determine the network allocation to maximize the amount of $\mathrm{CO}_{2}$ captured and stored in the system that has been given. Description of the details on the model details will be given in the following section.

\section{Results}

Objective function on this issue is the maximum value of the total load that can be exchanged from Source to Sink in the system. Defined as follows:

$$
\begin{gathered}
\max \sum_{i} \text { Source } i \\
\text { Source } i=\sum_{j}\left(t_{i j \text { end }}-t_{i j \text { start }}\right) * S_{i j} * b_{i j} \quad \vee i, j
\end{gathered}
$$

Where $i$ is the number of Source and $j$ is the amount Sink contained in the existing system. $T_{i j}$ end is the expiration of the Source and Sink in particular simultaneously so that the load is on Source stops distributed at the end of the year. For $T_{i j}$ start $t$ itself was started in a certain time of the Source and Sink simultaneously so that the existing load on the source can be distributed to the Sink. $S_{\mathrm{ij}}$ is the large flowrate of Source that will fit into Sink and matched with the injectivity Sink receptions on build up distribution. $b_{i j}$ are the parameters of the exchange of Source and Sink are assumed to have a value of 1 if source can be exchanged with Sink $j$ and is 0 if the source is not interchangeable with Sink $\mathrm{j}$. As for the source $\mathrm{i}$ is the amount of load that is exchanged from source $\mathrm{i}$ to one destination Sink.

$$
\sum_{i}\left(t_{i j \text { end }}-t_{i j \text { start }}\right) * S_{i j} * b_{i j} \leq S_{j} *\left(t_{j \text { end }}-t_{j}\right) \quad \vee i, j
$$

$\mathrm{S}_{\mathrm{j}}$ is the injectivity of $\mathrm{CO}_{2}$ that can be accepted by Sink $\mathrm{j}$ or can be called flowrate limits that go into storage (Sink) are available in the system. $\mathrm{S}_{\mathrm{j}}$ value is the maximum value of $\mathrm{CO}_{2}$ flowrate acceptable so flowrate entering into Sink $\mathrm{j}$ must be less than or equal to the flowrate limits available. $t_{j e n d}$ is the end of the their time Sink $j$ and $t_{j}$ is the time of the beginning of their Sink $j$ available. Flowrate of Source that goes into Sink should not exceed the limits specified injectivity and also right in that allowed for the distribution. 


$$
\sum_{j} b_{i j} \leq 1 \quad \vee i, j
$$

$\mathrm{b}_{\mathrm{ij}}$ are the parameters of the exchange of Source and Sink. Assumed value $\mathrm{b}_{\mathrm{ij}}$ only 0 and 1 . Equal to 0 when the source $i$ is not interchangeable with Sink $\mathrm{j}$. While the value of 1 means the Source $\mathrm{i}$ can be exchanged with Sinkj. The value of this parameter should not be more than 1 when the Source i. It is intended Source i only can be distributed to one of the existing j Sink or can not be divided or broken because when shared will add to the total cost to manufacture the piping network between Source and Sink.

$$
t_{i j \text { start }} \geq t_{j} \quad \vee i, j
$$

$\mathrm{T}_{\mathrm{ij} \text { start }}$ is the start time of the year so many of Source and Sink simultaneously so that the existing load on the source can be distributed to the Sink. $\mathrm{T}_{\mathrm{ij} \text { start }}$ value of more than or equal to the start time of the construction of a storage or Sink $\mathrm{j}$.

$$
t_{i j \text { start }} \geq t_{i} \quad \vee i, j
$$

$\mathrm{T}_{\mathrm{ij} \text { start }}$ value of more than or equal to the start time of the construction of a plant producing $\mathrm{CO}_{2}$ or Source $\mathrm{i}$. This means that $T_{i j}$ worth between or equal to $t_{i}$ or $t_{j}$, taken years to so many of the greatest (both pass throughthe year). For example, if $t_{i}$ is equal to the value 0 and $t_{j}$ is equal to the 5 th year, the $T_{i j}$ optimum for the 5 th years in since $t_{i}$ also pass through the 5 th year, while new $t_{j}$ starting in year 5 .

$$
t_{i j \text { end }} \leq t_{j \text { end }} \quad \vee i, j
$$

$\mathrm{T}_{\mathrm{ij} \text { end }}$ is the end time of they year so many of Source and Sink simultaneously so that the $\mathrm{CO}_{2}$ is in the Source can stop distributed because of the age of existing storage. $T_{i j}$ end value of less than or equal to the expiration of a storage or Sink j.

$$
t_{i j \text { end }} \leq t_{i \text { end }} \quad \vee i, j
$$

$\mathrm{T}_{\mathrm{ij}}$ end value of less than or equal to the time of the end of the completion of a plant producing $\mathrm{CO}_{2}$ or Source $\mathrm{i}$. This means that the end $T_{i j}$ worth between or equal to $t_{i}$ or $t_{j}$, taken so many years to the smallest (both pass through the year). For example, if the value is equal to $t_{i \text { end }}$ to the year-end 30 and $t_{j}$ is equal to the $50^{\text {th }}$ (if the start of the same year 0 ) then $t_{i j e n d}$ optimum lies in the 30th year since $t_{j}$ also passed the 30 th year, while $t_{i}$ ended in 30th year and it was not until the 50th.

$$
S_{i j} \leq S_{j} \quad \vee i, j
$$

$\mathrm{S}_{\mathrm{ij}}$ is a large amount of $\mathrm{CO}_{2}$ flowrate distributed from the Source and Sink. $\mathrm{S}_{\mathrm{ij}}$ value of less than or equal to limit $\mathrm{CO}_{2}$ injectivity of Source that goes into Sink j.

$$
S_{i j} \leq S_{i} \quad \vee i, j
$$

$\mathrm{S}_{\mathrm{ij}}$ value of less than or equal to the flowrate of $\mathrm{CO}_{2}$ at a plant producing $\mathrm{CO}_{2}$ or Source i. This means that $\mathrm{S}_{\mathrm{ij}}$ worth between or equal to $\mathrm{S}_{\mathrm{j}}$ or $\mathrm{S}_{\mathrm{i}}$, taken large flowrate is the smallest that can be entered into the storage (flowrate magnitude does not exceed a predetermined). For example, if the value of $S_{i}$ equal to $10 \mathrm{Mt} / \mathrm{year}$ and $\mathrm{S}_{\mathrm{j}}$ is equal to $5 \mathrm{Mt} / \mathrm{year}$ of the $\mathrm{S}_{\mathrm{i}}$ optimum that can be exchanged at $5 \mathrm{Mt} /$ year because of restrictions flowrate entering into Sink $\mathrm{j}$ at $5 \mathrm{Mt} / \mathrm{year}$.

$$
\sum_{i} S_{i j} * b_{i j} \leq S_{j} \quad \vee i, j
$$

The value of the amount of $\mathrm{CO}_{2}$ that can be distributed flowrate from various source $i$ to the Sink $\mathrm{j}\left(\mathrm{S}_{\mathrm{ij}}\right)$ is less than or equal to the value of the injectivity of $\mathrm{CO}_{2}$ that can be accepted by Sink $\mathrm{j}$. This means that the $\mathrm{CO}_{2} \operatorname{Sink} \mathrm{j}$ can receive in accordance with the restrictions set to get in on the $\mathrm{j}$ Sink. For example, if the Source 1 produces $\mathrm{CO}_{2}$ of $5 \mathrm{Mt} /$ year and Source 2 produces $\mathrm{CO}_{2}$ of $3 \mathrm{Mt} /$ year in the same year. Then Sink 1 has a limit incoming flowrate of $10 \mathrm{Mt} /$ year in the same year as the source, then the $\mathrm{CO}_{2}$ from the Source 1 and Source 2 can be accommodated by Sink 1 because the value of the Source 1 and Source 2 is less than the limits acceptance $\mathrm{CO}_{2}$ flowrate at Sink 1.

$$
\left(t_{i j \text { end }}-t_{i j \text { start }}\right) \geq t^{\text {min }} * b_{i j} \quad \vee i, j
$$

The distance in between $\mathrm{T}_{\mathrm{ij} \text { end }}$ or the expiration of the distribution of $\mathrm{CO}_{2}$ from Source to Sink with $\mathrm{T}_{\mathrm{ij} \text { start }}$ or the initiation of distribution Source to Sink must be greater than $t^{\min }$ with $b_{i j}$ factors. $t^{\min }$ is the minimum time given distance. In this case $t^{\min }$ used is equal to 0 so that the distance $T_{i j}$ end ${ }^{\text {and }} T_{i j}$ start $m u s t$ be greater than 0 . Not the same as possible if the distance is worth less than 0 or negative.

For the analysis of cost calculation, its objective function changed as follows:

$$
\min \sum_{i} \text { Source } i
$$




$$
\text { Source } i=\sum_{j}\left(\left(t_{i j \text { end }}-t_{i j \text { start }}\right) * S_{i j} * \text { capture cost }+ \text { distance }_{i j} * \text { pipeline cost }\right) * b_{i j} \vee i, j
$$

With capture cost equals with $\$ / \mathrm{Mt}_{\text {captured }}$. Added to the price of pipeline being built between the Source and Sink are available (pipeline cost equals with $\$ / \mathrm{km}$ ). And added the correction factor:

$$
\begin{array}{ll}
\sum_{i} \sum_{j} b_{i j} \geq 1 & \vee i, j \\
\sum_{i} \sum_{j} b_{i j} \leq \operatorname{smax} & \vee i, j
\end{array}
$$

Where smax isthe total number of available source. The results obtained later is the maximum flowrate or large objective function that can be distributed from Source to Sink at the appropriate time. Also obtained the most optimal network in the distribution Source Sink $\mathrm{i}$ to $\mathrm{j}$ so that it can be made after the grid diagram of the system.

To use the model above, use the following assumptions:

1. CCS system consists of $\mathrm{m}$ Source $\mathrm{CO}_{2}$ and $\mathrm{n}$ Sink $\mathrm{CO}_{2}$. Source and Sink can begin to operate at any time in the planning.

2. Each i Source $\mathrm{CO}_{2}(\mathrm{i}=1,2, \ldots, \mathrm{m})$ is characterized by $\mathrm{CO}_{2}$ capture flowrate corresponding to the maximum potential of the exhaust gas removal plant. In addition, the operation of each source $\mathrm{i}$, also defined.

3. Each $\mathrm{j}$ Sink $\mathrm{CO}_{2}(\mathrm{i}=1,2, \ldots, \mathrm{n})$ is characterized by the upper limit for $\mathrm{CO}_{2}$ storage capacity, the maximum rate at which $\mathrm{CO}_{2}$ can be injected into any given Sink. Both of these characteristics are based on the geological characteristics of the storage site.

4. Source and Sink located in one geographical area.

The modelis implemented using commercial modeling software Lingo 14.0 using a PC with a $1.7 \mathrm{GHz}$ processor and 4 GB of RAM. In both cases, the solution found ignores time simulation process.

\section{Discussion}

For the implementation of this model, is used as a case study follows (taken by Lee et al., 2014):

Table 1. Source Data

\begin{tabular}{ccccc}
\hline Source & $\begin{array}{c}\mathrm{CO}_{2} \text { flowrate } \\
(\mathrm{Mt} / \mathrm{y})\end{array}$ & $\begin{array}{c}\mathrm{CO}_{2} \text { Load } \\
(\mathrm{Mt})\end{array}$ & $\begin{array}{c}\text { Start Time } \\
(\mathrm{y})\end{array}$ & $\begin{array}{c}\text { End Time } \\
(\mathrm{y})\end{array}$ \\
\hline 1 & 4 & 120 & 0 & 30 \\
2 & 5 & 200 & 0 & 40 \\
3 & 2.5 & 62.5 & 5 & 30 \\
4 & 8 & 240 & 10 & 40 \\
5 & 5 & 200 & 0 & 40 \\
6 & 3 & 120 & 10 & 50 \\
Total & & 942.5 & & \\
\hline
\end{tabular}

Table 2. Sink Data

\begin{tabular}{cccc}
\hline Sink & $\begin{array}{c}\text { Injectivity } \\
(\text { Mtty) }\end{array}$ & $\begin{array}{c}\text { StorageCapacity } \\
\text { (Mt) }\end{array}$ & $\begin{array}{c}\text { Earliest } \\
\text { time } \\
\text { available } \\
\text { (y) }\end{array}$ \\
\hline 1 & 5 & 200 & 0 \\
2 & 10 & 400 & 10 \\
3 & 10 & 250 & 15 \\
Total & & 850 & \\
\hline
\end{tabular}


Figure 1 illustrates all the possibilities of the distribution of $\mathrm{CO}_{2}$ from Source to Sink there. All probability is the Source 1 can be distributed to Sink 1, Sink 2, and Sink 3, as well as others. Determination of the maximum that can be distributed based on the mathematical model in the form of constraints that have been described above.

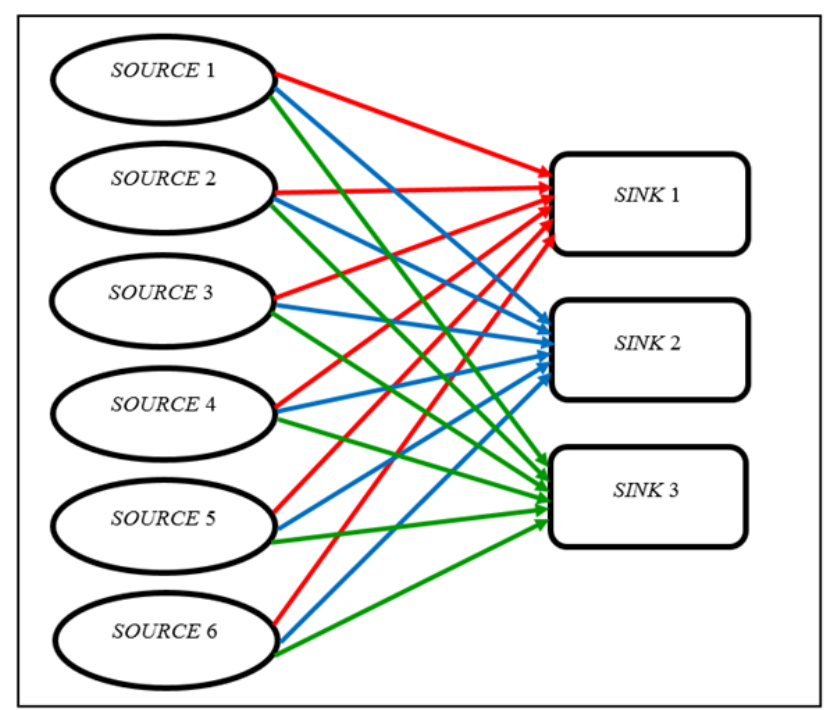

Figure 1. All possible distribution of $\mathrm{CO}_{2}$

From the simulation results, obtained from objective function or the maximum load that can be exchanged is at $670 \mathrm{Mt}$, or $71.09 \%$ of the total generated source. Sink 1 can receive $\mathrm{CO}_{2}$ from Source 5 of $200 \mathrm{Mt}$, so storage is not trace or fully charged. Source 5 has a flowrate of $\mathrm{CO}_{2}$ that will be incorporated into the Sink by $5 \mathrm{Mt} / \mathrm{year}$ while the Sink 1 has a limited $\mathrm{CO}_{2}$ injection at $5 \mathrm{Mt}$ /year, so that the $\mathrm{CO}_{2}$ out of 5 Source distributed into Sink Sink 1. While Sink 2 may receive $\mathrm{CO}_{2}$ from Source 2 and Source 6 as much as $150 \mathrm{Mt}$ and 120 Mt so the rest of this storage is at $130 \mathrm{Mt}$. Source 2 has a flowrate of $\mathrm{CO}_{2}$ that will be injected into the Sink by $5 \mathrm{Mt} / \mathrm{year}$ while $\mathrm{CO}_{2}$ flowrate in Source 6 have to be incorporated into the Sink by $3 \mathrm{Mt} /$ year.Sink 2 has a limitation of $\mathrm{CO}_{2}$ that goes by $10 \mathrm{Mt}$ /year so that the $\mathrm{CO}_{2}$ out of the Source 2 and Source 6 is distributed into Sink 2 because it meets the limits of $\mathrm{CO}_{2}$ that goes in Sink 2. Sink 3 can receive the $\mathrm{CO}_{2}$ from the Source 4 of $200 \mathrm{Mt}$ and the rest of this storage is at $50 \mathrm{Mt}$.Source 4 has a flowrate of $\mathrm{CO}_{2}$ that will be incorporated into the Sink of $8 \mathrm{Mt} /$ year while Sink 3 have limitations diinjekkan $\mathrm{CO}_{2}$ by $10 \mathrm{Mt}$ /year so that the $\mathrm{CO}_{2}$ out of the Source 4 distributed into Sink 3 . The result is the most optimal results for distribution according to the $\mathrm{CO}_{2}$ flowrate out of Source $\mathrm{i}$ and $\mathrm{CO}_{2}$ acceptance limits specified in the Sink $\mathrm{j}$ at time availability of Source and Sink simultaneously.

The above interpretation of the model Source 1 can not be accommodated. So also with the Source 3 . This is caused because of the limits set for the entry of $\mathrm{CO}_{2}$ Sink, thus the Sink can not receive all of the $\mathrm{CO}_{2}$ that comes from Source despite existing storage remains. Source 2 and Source 4 can not be accommodated on the existing Sink. Source 2 in year 0 to year 10 , the $\mathrm{CO}_{2}$ from the plant can not be accommodated in storage because in the Sink 2 began in the 10th year. For Source 4 in year 10 to year $15, \mathrm{CO}_{2}$ can not be accommodated in the storage / Sink 3 because in that year Sink 3 has not been in operation and Sink 3 only can be used on its 15 th year. So that the network according to this study is the Source 2 distributed to Sink 2, Source 4 to Sink 3, Source 5 to Sink 1 , and Source 6 to Sink 2. The simulation results can be represented in the grid diagram as follows: 


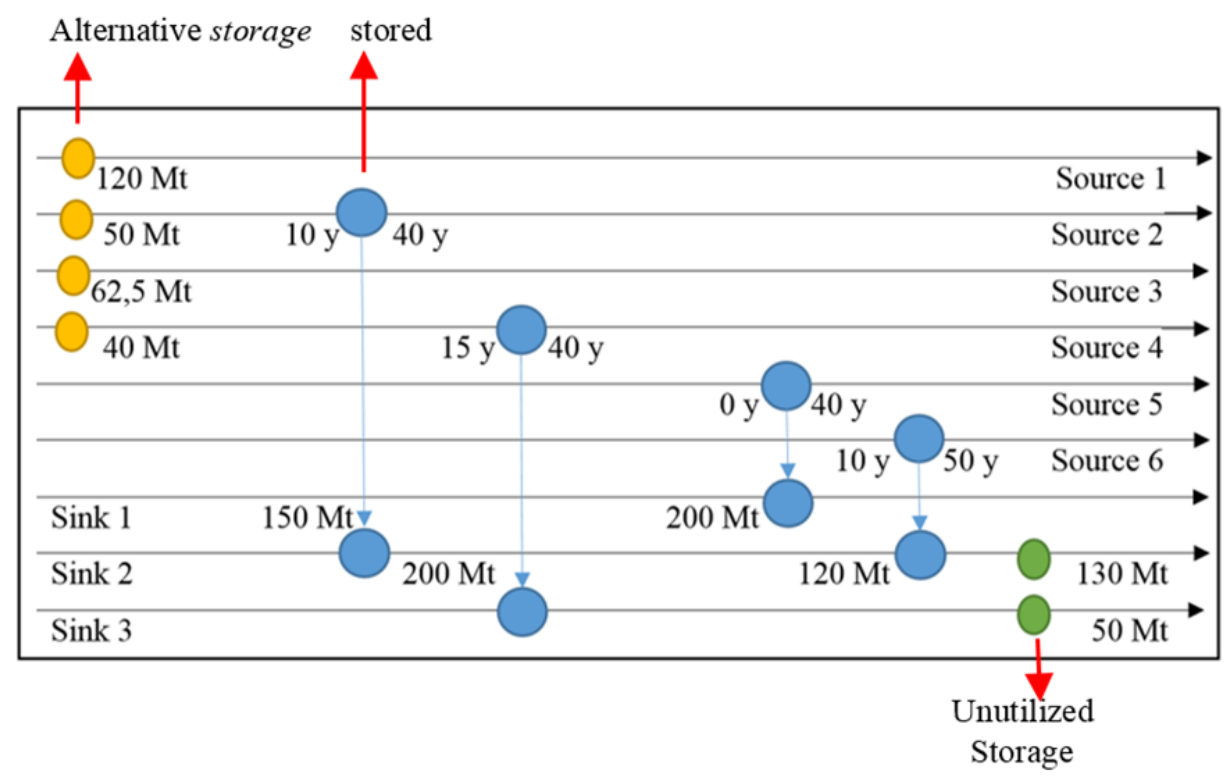

Figure 2. Grid diagram for optimal Source-Sink matching in case above

As for the implementation of cost calculation, added data in table.3. In this study, taken on site layout Sink, Sink 2, and Sink 3 respectively, Purbalingga (Central Java), Blora (Central Java), and Garut (West Java).

Table 3. Approximate Distance from Source-Sink

\begin{tabular}{|c|c|c|c|c|}
\hline Source & Rate $(\mathrm{Mt} / \mathrm{y})$ & Source Name & & Distance $(\mathrm{km})$ \\
\hline \multirow{3}{*}{1} & \multirow{3}{*}{4} & \multirow{3}{*}{ PJB UP Muara Karang } & Sink 1 & 318.03 \\
\hline & & & Sink 2 & 521.39 \\
\hline & & & Sink 3 & 174.92 \\
\hline \multirow{3}{*}{2} & \multirow{3}{*}{5} & \multirow{3}{*}{ Semen Gresik (Tuban) } & Sink 1 & 281.25 \\
\hline & & & Sink 2 & 55.42 \\
\hline & & & Sink 3 & 443.71 \\
\hline \multirow{3}{*}{3} & \multirow{3}{*}{2.5} & \multirow{3}{*}{ Chandra Asri } & Sink 1 & 400.02 \\
\hline & & & Sink 2 & 605.58 \\
\hline & & & Sink 3 & 248.72 \\
\hline \multirow{3}{*}{4} & \multirow{3}{*}{8} & \multirow{3}{*}{ PJB UP Paiton } & Sink 1 & 453.6 \\
\hline & & & Sink 2 & 243.9 \\
\hline & & & Sink 3 & 618.9 \\
\hline \multirow{3}{*}{5} & \multirow{3}{*}{5} & \multirow{3}{*}{ PJB UP Gresik } & Sink 1 & 359.96 \\
\hline & & & Sink 2 & 138.38 \\
\hline & & & Sink 3 & 525.22 \\
\hline \multirow{3}{*}{6} & \multirow{3}{*}{3} & \multirow{3}{*}{ Pertamina blok Cepu } & Sink 1 & 309.37 \\
\hline & & & Sink 2 & 515.08 \\
\hline & & & Sink 3 & 165.69 \\
\hline
\end{tabular}

From the simulation results, obtained from objective function or minimum cost for the construction of piping 
between the Source and Sink that can be exchanged is for $\$ 9,509,656$ (taking assume capture cost equals $\$ 14.55$ $\$ / \mathrm{Mt}_{\text {captured }}$ and pipeline cost equals with $3100 \$ / \mathrm{km}$ distance) with load exchanged for $650 \mathrm{Mt}$ or $68.97 \%$ of the total generated source.Sink 1 can receive $\mathrm{CO}_{2}$ from the Source 4 as much as $150 \mathrm{Mt}$, so this storage remaining 50 Mt. Source 4 has a flowrate of $\mathrm{CO}_{2}$ thatwill be incorporated into the Sink of $8 \mathrm{Mt} /$ year while the Sink 1 has a $\mathrm{CO}_{2}$ injection limit at $5 \mathrm{Mt} /$ year so that the $\mathrm{CO}_{2}$ out of the Source 4 distributed into Sink 1 of $5 \mathrm{Mt} / \mathrm{year}$ and 3 $\mathrm{Mt} /$ year $\mathrm{CO}_{2}$ at Source 4 can not captured or wasted. While the Sink 2 can receive $\mathrm{CO}_{2}$ from the Source 1, Source 3 and Source 6 respectively, $80 \mathrm{Mt}, 50 \mathrm{Mt}$ and $120 \mathrm{Mt}$ so the rest of this storage is at $150 \mathrm{Mt}$. Source 1 has a flowrate of $\mathrm{CO}_{2}$ that will be included in the Sink by $4 \mathrm{Mt} / \mathrm{year}$, Source 3 of $2.5 \mathrm{Mt} /$ year, while the $\mathrm{CO}_{2}$ flowrate in Source 6 have to be put in the Sink by 3Mt/year. Sink 2 has a limitation of $\mathrm{CO}_{2}$ that goes in by $10 \mathrm{Mt} / \mathrm{year}$ so that the $\mathrm{CO}_{2}$ out of the Source 1, Source 3, and Source 6 distributed into Sink 2 because it meets the incoming $\mathrm{CO}_{2}$ limits in Sink 2. Sink 3 can receive $\mathrm{CO}_{2}$ from Source 2 and Source 5 respectively of $125 \mathrm{Mt}$ and storage does not have the rest of storage. Source 2 has a flowrate of $\mathrm{CO}_{2}$ that will be incorporated into the Sink by $5 \mathrm{Mt} /$ year. Likewise with Source 5. While Sink 3 have a $\mathrm{CO}_{2}$ injection limitations by $10 \mathrm{Mt} / \mathrm{year}$ so that the $\mathrm{CO}_{2}$ out of the Source 2 and Source 5 distributed into Sink 3. These results are the most optimal results for distribution in accordance with the flowrate of $\mathrm{CO}_{2}$ out of the Source $\mathrm{i}$ and $\mathrm{CO}_{2}$ acceptance limits specified in the Sink $\mathrm{j}$ at time availability of Source and Sink simultaneously, also with the most minimal cost calculation for the construction of pipelines from source $\mathrm{i}$ to sink $\mathrm{j}$.

\begin{tabular}{|lllllll}
\hline & & & & \\
\hline $70 \mathrm{Mt}$ & & & & \\
\hline
\end{tabular}

Figure 3. Grid diagram for optimal cost in Source-Sink matching

From the above interpretation of the model all Source (Source 1, 2, 3, 4 and 5) can not be accommodated on the existing Sink. Source 1 in year 0 to year 10 , the $\mathrm{CO}_{2}$ from the plant can not be accommodated in storage because in the Sink 2 began in the 10th year. Source 2 in year 0 to year 15 , the $\mathrm{CO}_{2}$ from the plant can not be accommodated in storage because in the Sink 3 began in the 15th. Source 3 in year 5 to year 10 , the $\mathrm{CO}_{2}$ from the plant can not be accommodated in storage because in the Sink 2 began in the 10th year. As for Source $4, \mathrm{CO}_{2}$ from the plant can not be accommodated fully into storage because flowrate constraints into the Sink 1 is at 5 $\mathrm{Mt} / \mathrm{year}$ and large flowrate $\mathrm{CO}_{2}$ out of the Source 4 is equal to $8 \mathrm{Mt} / \mathrm{year}$ so that entry into Sink 1 is at $5 \mathrm{Mt} / \mathrm{year}$ and $3 \mathrm{Mt} /$ year discarded. Source 5 in year 0 to year 15, $\mathrm{CO}_{2}$ can not be accommodated in the Sink 3 because in that year Sink Sink 3 has not been in operation and 3 can be used on its 15 th year. So that the network according to this study is the Source 1 distributed to Sink 2, Source 2 to 3 Sink, Source 3 to Sink 2, Source 4 to Sink 1, Source 5 to Sink 3 and Source 6 to Sink 2. In this optimization, mathematical model and the constraint set is affecting the results obtained. Likewise with known data also affect the results obtained. Network modeling obtained at each different from one another due to differences in the specified constraints. For modeling 1 is influenced by the limits of $\mathrm{CO}_{2}$ flowrate into the Sink and Sink end time of the operation. And for modeling 2, network distribution of $\mathrm{CO}_{2}$ from Source to Sink influenced by the minimum cost results obtained in the development of existing piping. Thus can be concluded a simple model has been developed for optimal matching of Source and Sink $\mathrm{CO}_{2}$ in CCS systems are limited by the temporal period, the rate of injectivity, and storage capacity constraints. Two illustrative case studies have been completed and resulted in exchange efficiency of $71.09 \%$ and $68.97 \%$. Matching generated from this model can be changed if the variable costs are taken into account. 


\section{Acknowledgments}

This paper was made as one of the requirements for obtaining a bachelor's degree in chemical engineering in the department of chemical engineering, Institut Teknologi Sepuluh Nopember, Surabaya - Indonesia.The authors also wish to thank Professor Dr. Ir. Ali Altway MSc., Institut Teknologi Sepuluh Nopember, Indonesia, for his advice, support, and valuable criticism.

\section{References}

Ambrose, W.A. Breton, C., Holtz, M.H., Nunez-Lopez, V., Hovorka, S. D., \& Duncan, I.J. (2009). CO2 source-sink matching in the lower 48 United States, with examples from the Texas Gulf Coast and Permian Basin. Environmental Geology 57, 1537-1551.http://dx.doi.org/10.1007/s00254-008-1430-x

Brunsvold, A., Jakobsen, J.P., Husebye, J., \& Kalinin, A. (2011). Case studies on CO2 transport infrastructure: Optimization of pipeline network, effect of ownership, and political incentives. Energy Procedia 4, 3024-3031.http://dx.doi.org/10.1016/j.egypro.2011.02.213

Condor, J., Unatrakarn, D., Asghari, K., \& Wilson, M. (2011). Current status of CCS initiatives in the major emerging economies. Energy Procedia 4, 6125-6134. http://dx.doi.org/10.1016/j.egypro.2011.02.620

Davison, J., Freund, P., \& Smith, A. (2001). Putting carbon back into the ground, Cheltenham: International Energy Agency Greenhouse Gas R\&D Programme.

Diamante, J. A. R., Tan, R. R., Aviso, K. B., Bandyopadhyay, S., Ng, D. K. S., Foo, D. Y. (2013). “Unified Graphical Pinch Approach for Targeting of Carbon Capture and Sequestration (CCS) Systems over Multiple Time Periods". Proceedings of the 6th International Conference on Process Systems Engineering (PSE ASIA)25 - 27 June 2013. Kuala Lumpur.

IEA (2010). Technology Roadmap: Carbon Capture and Storage. International Energy Agency, Paris.

Kazmierczak, T., Brandsma, R., Neele, F., \& Hendriks, C. (2009). Algorithm to create a CCS low-cost pipeline network. Energy Procedia 1, 1617-1623.http://dx.doi.org/10.1016/j.egypro.2009.01.212

Lee, Jui-Yuan, R.R. Tan, Cheng-Liang Chen. (2014). A unified model for the deployment of carbon capture and storage. Applied Energy 121, 140-148.http://dx.doi.org/10.1016/j.apenergy.2014.01.080

Middleton, R.S., \& Bielicki, J.M. (2009). A comprehensive carbon capture and storage infrastructure model. Energy Procedia 1, 1611-1636.http://dx.doi.org/10.1016/j.egypro.2009.01.211

Middleton, R.S., \& Bielicki, J.M. (2009). A scalable infrastructure model for carbon capture and storage: SimCCS. Energy Policy 37, 1052-1060.http://dx.doi.org/10.1016/j.enpol.2008.09.049

Pekala, L.M., Tan, R.R., Foo, D.C.Y., \& Jezowski, J. (2010) Optimal energy planning models with carbon footprint constraints. Applied Energy 87, 1903-1910.http://dx.doi.org/10.1016/j.apenergy.2009.12.012

Pires, J.C.M., Martins, F.G., Alvim-Ferraz, M.C.M., \& Simoes, M. (2011). Recent developments on carbon capture and storage: An overview. Chemical Engineering Research and Design, 89, 1446-1460.http://dx.doi.org/10.1016/j.cherd.2011.01.028

Stangelend, A. (2007) “A Model for The $\mathrm{CO}_{2}$ Capture Potential”. International Journal of Greenhouse Gas Control, 1, 418.http://dx.doi.org/10.1016/S1750-5836(07)00087-4

Tan, R.R., Aviso, K.B., Bandyopadhyay, S., Ng, D.K.S., 2013. Optimal source - sinkmatching in carbon capture and storage systems with time, injection rate, and capacity constraints. Environmental Progress and Sustainable Energy32, 411-416.http://dx.doi.org/10.1021/ie402866d

Turk, G.A., Cobb, T.B., Jankowski, D.J., Wolsky, A.M. \& Sparrow, F.T. (1987). CO2 transport: A new application of the assignment problem. Energy Procedia 123-130.http://dx.doi.org/10.1016/0360-5442(87)90116-2

\section{Copyrights}

Copyright for this articleis retained by the author(s), with first publication rights granted to the journal.

This is an open-access article distributed under the terms and conditions of the Creative Commons Attribution license (http://creativecommons.org/licenses/by/3.0/). 